\title{
Avaliação dos egressos do Programa de Educação Tutorial (PET) do curso de Odontologia da Universidade Federal de Pelotas
}

\author{
Laura Lourenço Morel*; Nadine Barbosa Ferreira*; Juliana Garcia Altmam*; Heloisa Grehs \\ e Silva**; Eduardo Trota Chaves***; Josué Martos****
}

* Graduando em Odontologia, Bolsista do PET, Faculdade de Odontologia, Universidade Federal de Pelotas

** Mestranda em Clínica Odontológica (Endodontia), Programa de Pós-Graduação em Odontologia, Universidade Federal do Rio Grande do Sul

*** Mestrando em Ciências Odontológicas (Dentística), Programa de Pós-Graduação em Ciências Odontológicas, Universidade Federal de Santa Maria

**** Professor Titular, Tutor do PET, Faculdade de Odontologia, Universidade Federal de Pelotas

Recebido em 28/05/2020. Aprovado em 16/07/2020.

\begin{abstract}
RESUMO
O objetivo desse trabalho foi avaliar o perfil profissional dos egressos da Faculdade de Odontologia da Universidade Federal de Pelotas, participantes do Programa de Educação Tutorial (PET). Foi realizada uma pesquisa descritiva, de natureza qualitativa e quantitativa, utilizando um questionário eletrônico estruturado e autoaplicável como instrumento de coleta e enviado, via correspondência eletrônica, à todos os egressos que participaram efetivamente do grupo PET e aceitaram participar desta pesquisa. Atividade profissional, níveis de formação e objetivos propostos pelo programa foram avaliados. O total de egressos foi de 89, desde a criação do grupo, em 1992, até o ano de 2019. Com as respostas obtidas $(n=59)$, verificou-se que maior parte dos egressos que aderiram a pesquisa concluíram o curso entre os anos de 2004 até 2018 (59.3\%), e apenas 24 (40.6\%) em período anterior a 2004 . Verificou-se que $25 \%$ atuam no serviço público, $44 \%$ no setor privado e $22 \%$ atuam em ambos. Em relação à titulação, apenas $4(6,8 \%)$ não possuem nenhuma pós-graduação, e $53(89.8 \%)$ atuam na região Sul do país, $36(61 \%)$ são do sexo feminino e $23(39 \%)$ do masculino. Ao final do questionário, foi perguntado a respeito da influência da participação no Programa sobre a trajetória profissional, com uma escala de intensidade progressiva de 1 a 5 , gerando 19 respostas com nível 4 e 39 respostas com nível 5. Os resultados evidenciaram uma influência muito positiva da participação no Programa na vida profissional de seus ex-participantes, tanto no mercado de trabalho, quanto na vivência de pós-graduação.
\end{abstract}

Descritores: Odontologia. Educação Superior. Avaliação Educacional. 


\section{INTRODUÇÃO}

As universidades apresentam, entre tantas atribuições e obrigações, a função primordial de formação profissional, preparando profissionais para as carreiras de base intelectual, científica e técnica; a busca e o desenvolvimento do saber humano e a transmissão do produto de seu conhecimento para a sociedade ${ }^{1}$. A função social da universidade, contudo, vai além da preparação para o mercado de trabalho, avaliando os problemas coletivos e articulando de tal forma que universidade e sociedade estejam conectadas e trabalhando de forma harmônica ${ }^{2}$. A universidade brasileira, desta forma, sustenta-se em três pilares (ensino, pesquisa e extensão) indispensáveis e fundamentais para a construção do conhecimento com qualidade e produtividade.

Neste aspecto, a aquisição de conhecimentos, habilidades e competências dependem de um processo de ensinoaprendizagem que estabeleça a conexão entre a teoria e a prática, ligando ciência e trabalho ${ }^{3}$. Contudo, o que se observa por vezes é um distanciamento da universidade associado a um ensino descontextualizado, com pesquisas que não estabelecem nexo com a realidade social do curso $^{2}$.

A partir deste contexto, o Programa de Educação Tutorial (PET) se desenvolve por meio de grupos de estudantes com tutoria docente e organizados a partir de formações no nível de graduação nas instituições de ensino superior (IES) do País, orientados pelo princípio da indissociabilidade plena entre ensino, pesquisa e extensão. O PET foi criado pela CAPES em 1979, com base na experiência bemsucedida do professor Yvon Leite de Magalhães Pinto da Universidade Federal de Minas Gerais, com o nome de Programa Especial de Treinamento, no qual oferecia-se aos bolsistas uma formação acadêmica no mais alto grau de excelência com o intuito de prepará-los e incentivá-los a ingressar em programas de pósgraduação e, posteriormente, na docência universitária ${ }^{4}$. Atualmente o PET instituído nas universidades do país atua a partir do desenvolvimento de ações coletivas e de caráter interdisciplinar, objetivando a formação de cidadãos com ampla visão do mundo e com responsabilidade social ${ }^{5}$. Os reflexos destas ações seriam a qualificação do desempenho acadêmico, dos cursos de graduação nos quais os grupos estivessem inseridos, nos cursos de pósgraduação e, não menos importante, dos próprios profissionais inseridos no mercado de trabalho ${ }^{4,6}$.

A institucionalização do PET proporcionou a consolidação de um trabalho tutorial de aprendizagem em favor da diversidade e sempre guiado pelos princípios basilares indissociáveis entre ensino, pesquisa e extensão. Atualmente, o PET conta com 842 grupos distribuídos em 121 instituições de ensino superior no País ${ }^{7}$.

O que se espera do PET é fomentar a formação de profissionais de nível superior, dotados de elevados padrões científicos, técnicos, éticos e com responsabilidade social, nas diversas áreas do conhecimento, e que estes sejam capazes de uma atuação no sentido da transformação da realidade nacional ${ }^{7}$. Neste sentido, a análise do perfil do egresso tem se mostrado uma importante ferramenta de avaliação dos cursos acadêmicos e programas estabelecidos nas IES com o intuito de identificar se a formação oferecida está impactando nas necessidades legítimas da população. Aliado a isto, a pesquisa com egressos permite saber se estes participantes efetivamente se apropriaram das informações, habilidades e ferramentas supostamente oferecidas pelo programa educativo proposto ${ }^{8-13}$.

Desta forma, foi objetivo deste estudo avaliar o perfil profissional dos egressos da Faculdade de Odontologia da Universidade 
Federal de Pelotas (FO-UFPel), participantes do Programa Especial de Treinamento/Programa de Educação Tutorial desde a sua criação no ano de 1992 até o ano letivo de 2018.

\section{METODOLOGIA}

Trata-se de pesquisa descritiva com delineamento transversal. Para a identificação da população-alvo foram empregados os dados físicos arquivados no programa, sendo identificados 89 petianos cadastrados nos registros do PET Odontologia FO-UFPel, compreendendo o período desde a criação do programa na instituição (1992) até o ano letivo de 2018. A população-alvo, após sua identificação, foi contatada por meio de redes sociais e correspondência eletrônica.

Este estudo foi preliminarmente submetido e aprovado pelo Comitê de Ética em Pesquisa institucional (CAAE: 81315317.0.0000.5318) e sua implementação seguiu todos os critérios prescritos pela Resolução 196/96 do Conselho Nacional de Saúde (CNS), que regulamenta sobre os princípios éticos para pesquisas biomédicas com seres humanos.

Todos os ex-petianos foram convidados a participar voluntariamente do estudo e, após ciência da pesquisa, concordaram de forma escrita via correspondência eletrônica após a leitura do Termo de Consentimento Livre e Esclarecido (TCLE).

Foi utilizado um questionário eletrônico estruturado e autoaplicável como instrumento de coleta, composto por 36 questões, 27 de múltipla escolha e 9 questões abertas, divididas em 5 eixos.

Foi empregada uma árvore de codificação para análise de dados constituída por cinco categorias ou eixos de análises ${ }^{12}$ (quadro 1). Os três primeiros eixos abordaram questões referentes às informações pessoais, incluindo formação acadêmica, atuação profissional e satisfação profissional, respectivamente. Os apontamentos detalhados nos dois eixos seguintes referiram-se a aspectos relacionados aos objetivos propostos pelo programa, como a experiência e a visão sobre o PET.

Os dados qualitativos foram avaliados através da análise de seus conteúdos e os quantitativos através de uma análise descritiva por meio de uma distribuição absoluta e percentual, empregando o software Microsoft Excel 16.0 (Microsoft Corporation, Redmond, WA, EUA).

\section{RESULTADOS E DISCUSSÃO}

Foram identificados 89 egressos na base de dados do programa e, destes, foram obtidas 59 respostas efetivas, com taxa de resposta de $66 \%$. Apesar da elevada taxa de respondentes, houve uma parcela importante de ausentes devido às dificuldades de comunicação e localização destes por meio das redes sociais, endereços de correio eletrônico desatualizadas ou mesmo falecimentos.

Dentre os egressos do programa PET do curso Odontologia da UFPel que participaram do estudo, a maioria (61\%) é do gênero feminino, concordando com estudos anteriores que reforçam este perfil ${ }^{9,10,13-15}$. De acordo com dados do Conselho Federal de Odontologia (CFO), no ano de 2020 as mulheres já correspondiam a 56\% do total de cirurgiões-dentistas brasileiros, estabelecendo as mulheres como o maior contingente populacional da Odontologia no país.

Quanto ao ano de conclusão de curso, obtiveram-se representantes desde o ano de 1992 (1,6\%) até o ano de 2018 (3,3\%), notando-se que a maior parte dos egressos que aderiram à pesquisa concluíram o curso entre os anos de 2004 e 2018 (59.3\%), sendo apenas 24 (40,6\%) em período anterior a 2004. Após a conclusão do curso de Odontologia, nota-se discreta migração territorial dos egressos. Constatou-se que a maioria dos participantes ainda residem no estado do Rio Grande do Sul (78\%), enquanto 
alguns em Santa Catarina (8,5\%), Paraná (3,3\%) e em menor número em mais outros 6 estados.

Quadro 1. Árvore de codificação com as estratégias de avaliação dos eixos estudados (adaptado de Silva $^{12}$ ).

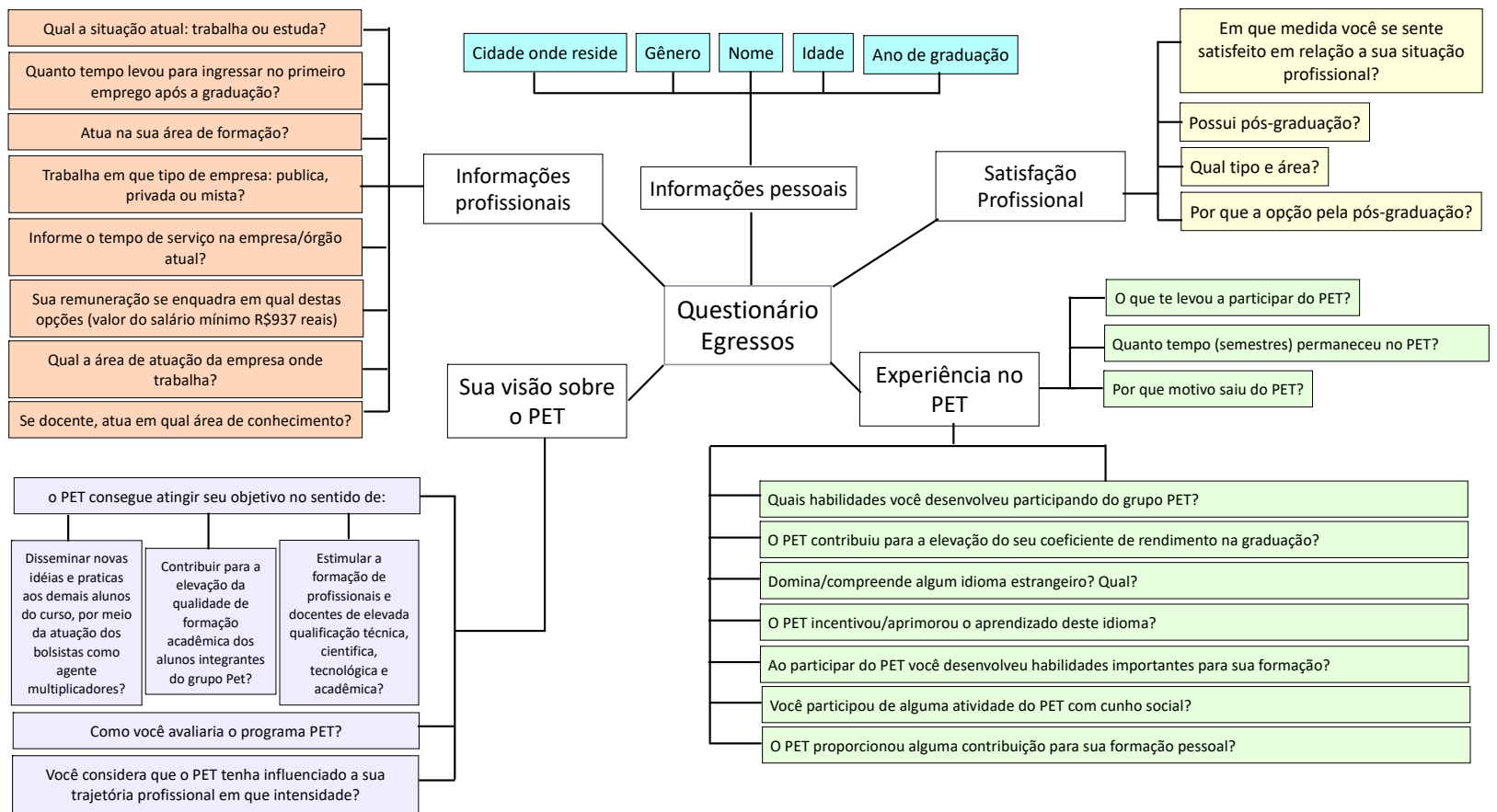

Quanto à atividade profissional desempenhada, os participantes relataram estudar e trabalhar em sua maioria $(50,8 \%)$, porém uma parcela importante dos respondentes tem dedicação exclusiva ao trabalho $(42,3 \%)$ e outra, menor, possui o estudo como atividade laboral (6,7\%) (tabela 1). Ainda, de acordo com a área de atuação profissional, os egressos afirmaram atuar na área de formação em Odontologia (98\%) e a maioria destaca a prestação de serviços em Odontologia (59,3\%), porém alguns atuam na área educacional (22\%) e áreas comerciais em geral (11,8\%). Em termos de mercado profissional, a Odontologia possibilita o trabalho em diversas modalidades, como atuação autônoma, serviço público e privado, além da inserção profissional em convênios ${ }^{16}$.

Também se torna muito importante ressaltar que $22 \%$ dos egressos atuam como docentes, corroborando com os resultados de outros estudos, nos quais se observou inserção acadêmica com percentuais oscilando em torno de $33,9 \%$ e $34,3 \%{ }^{12,13 .}$

A partir do questionamento sobre o tempo transcorrido entre a formatura e o ingresso no primeiro emprego, foi observado que uma parcela de 46 pessoas $(77,9 \%)$ obteve seu primeiro ofício em seis meses ou menos. Quando questionados sobre o caráter desse emprego, a maior parte dos egressos relatou que trabalha no setor privado (44\%), enquanto $25,4 \%$ trabalham no setor público. 
Tabela 1. Distribuição absoluta e percentual do perfil profissional dos egressos estudados

\begin{tabular}{|c|c|c|}
\hline Perfil Profissional & Categoria & Distribuição - n (\%) \\
\hline \multirow{3}{*}{ Situação profissional atual } & Somente estuda & $4(6,8)$ \\
\hline & Somente trabalha & $25(42,4)$ \\
\hline & Trabalha e estuda & $30(50,8)$ \\
\hline \multirow[t]{2}{*}{ Atua na área de formação } & Sim & $58(98,3)$ \\
\hline & Não & $1(1,7)$ \\
\hline \multirow[t]{5}{*}{ Atuação profissional } & Setor privado & $26(44,1)$ \\
\hline & Setor público & $15(25,4)$ \\
\hline & Setor público e privado & $13(22,0)$ \\
\hline & Empresa mista & $4(6,8)$ \\
\hline & Outros & $1(1,7)$ \\
\hline \multirow[t]{5}{*}{ Área de atuação } & Prestação de serviços & $35(59,3)$ \\
\hline & Educacional & $13(22,0)$ \\
\hline & Comercial & $7(11,9)$ \\
\hline & Industrial & $1(1,7)$ \\
\hline & Outros & $3(5,1)$ \\
\hline \multirow[t]{2}{*}{ Atua na docência } & Sim & $13(22,0)$ \\
\hline & Não & $46(78,0)$ \\
\hline \multirow[t]{8}{*}{ Remuneração mensal $^{\S}$} & Sem remuneração & $2(3,4)$ \\
\hline & $\leq 2$ salários mínimos & $5(8,5)$ \\
\hline & 3-6 salários mínimos & $9(15,3)$ \\
\hline & 7-10 salários mínimos & $21(35,6)$ \\
\hline & 11-14 salários mínimos & $13(22,0)$ \\
\hline & 15-18 salários mínimos & $3(5,1)$ \\
\hline & 19-22 salários mínimos & $2(3,4)$ \\
\hline & $\geq 23$ salários mínimos & $4(6,8)$ \\
\hline
\end{tabular}

${ }^{\S}$ Base salário mínimo: R\$937,00

No que diz respeito ao tempo de serviço desenvolvido nos diferentes setores de atuação, a maioria apresenta mais de 10 anos $(40,6 \%)$. Porém, alguns relataram um período menor, de 1 a 3 anos $(27,1 \%)$. No tocante à questão financeira, a remuneração mensal de $57,5 \%$ dos egressos entrevistados pode ser vista como acima da média, oscilando em torno de 7-10/11-14 salários mínimos ou mais. Contudo, os extremos também foram observados, como egressos sem remuneração $(3,3 \%)$ ou recebendo acima de 23 salários mínimos $(6,8 \%)$ (tabela 1$)$. Ao associar este dado com outros estudos pode-se observar que o rendimento médio mensal, encontrado em um percentual elevado de egressos, se distancia ligeiramente da realidade encontrada na literatura $^{10,21,22}$. A Odontologia é uma profissão que possibilita a atuação em diversas áreas, porém um contraponto real é a saturação do mercado de trabalho ${ }^{16}$ aliado à dificuldade em encontrar um emprego com uma boa remuneração.

Quando se analisa os dados do perfil acadêmico dos egressos do grupo PET 
Odontologia, percebe-se grande predileção pela atualização acadêmica, uma vez que 93,2\% afirmaram ter cursado ou estarem cursando um programa de pós-graduação, conforme ilustrado na tabela 2. Dessa parcela, a maioria relatou curso lato sensu concluído $(35,6 \%)$ ou em andamento (10,2\%). Alguns egressos relataram frequentar pós-graduação stricto sensu, como o mestrado $(16,9 \%)$ e/ou doutorado $(27,1 \%)$.

Estes dados, assim como de outros estudos, confirmam que a educação continuada e a titulação advindas de uma pós-graduação se configuram como um desígnio essencial para o mercado de trabalho ${ }^{13,17}$. É de grande importância ressaltar o elevado percentual de cursos lato sensu e stricto sensu concluídos ou em andamento (93,2\%), ressaltando-se que equivalência na oferta de vagas no mercado de trabalho nem sempre acontece ${ }^{9}$.

De acordo com os resultados, nota-se um grande interesse dos egressos na área da Cirurgia Bucomaxilofacial (15,2\%), seguido da Saúde Coletiva (13,5\%). No entanto, a grande maioria destaca não ter concentrado sua pós-graduação em uma única área, atuando em mais de uma especialidade (tabela 2). A predileção pela área cirúrgica corrobora com outros estudos avaliando estudantes de Odontologia ${ }^{15,18-20}$.

Tabela 2. Distribuição absoluta e percentual do perfil acadêmico dos egressos estudados

\begin{tabular}{llc}
\hline Perfil Acadêmico & Categoria & Distribuição n (\%) \\
\hline Possui pós-graduação & Sim & $55(93,2)$ \\
& Não & $4(6,8)$ \\
\hline Tipos de pós-graduação ${ }^{\S}$ & Especialização & $27(45,8)$ \\
& Mestrado & $10(16,9)$ \\
& Doutorado & $16(27,1)$ \\
& Pós-doutorado & $2(3,4)$ \\
& Não possui pós-graduação & $4(6,8)$ \\
\hline Áreas de pós-graduação & Cirurgia Bucomaxilofacial & $9(15,3)$ \\
& Dentística Restauradora & $2(3,4)$ \\
& Endodontia & $5(8,5)$ \\
& Periodontia & $1(1,7)$ \\
& Saúde Coletiva & $8(13,6)$ \\
& Estomatologia e Patologia & $1(1,7)$ \\
& Implantodontia & $1(1,7)$ \\
& Odontopediatria & $2(3,4)$ \\
& Ortodontia & $7(11,9)$ \\
& Prótese Dentária & $2(3,4)$ \\
& Mais de uma área & $17(28,8)$ \\
& Não possui pós-graduação & $4(6,8)$ \\
\hline Motivo da pós-graduação $\dagger$ & Aprimorar conhecimento & $46(38,3)$ \\
& Carreira acadêmica & $26(21,7)$ \\
& Exigência do mercado & $24(20,00)$ \\
& Opção financeira & $11(9,2)$ \\
& Outros & $13(10,8)$ \\
\hline \multirow{2}{*}{ Pos-gra } &
\end{tabular}

$\S$ Pós-graduação concluída ou em andamento. †Admitiu-se mais de uma resposta. 
Os motivos principais que levaram os participantes a entrar no programa foram desenvolver atividades de ensino, pesquisa e extensão (26\%), e estes permaneceram no PET entre 7 e 8 semestres letivos (59\%). Já os motivos que os levaram à saída do PET foram a finalização do curso $(93,2 \%)$ e a vontade de participar de outros programas (3,3\%). Ainda, 55 dos participantes $(93,2 \%)$ relataram que a participação contribuiu para o rendimento nas atividades da graduação. O total de 59 participantes $(100 \%)$ afirmou ter desenvolvido habilidades importantes para a sua formação, como capacidade de trabalhar em equipe, espírito de liderança e capacidade de desenvolver atitudes reflexivas, investigativas e questionadoras (gráfico 1).
Mediante a participação de atividades de cunho social desenvolvidas pelo grupo PET Odontologia da UFPel, os participantes em sua maioria $(83 \%)$ afirmaram ter participado destas atividades, contribuindo para a formação pessoal da totalidade dos egressos (100\%). Nos primórdios, como Programa Especial de Treinamento, não se compreendia a relevância de uma formação baseada no comprometimento social, sendo instruída esta particularidade dentro dos objetivos do Programa de Educação Tutorial após a edição do Manual de Orientações Básicas de $2002^{12}$. Portanto, por meio do ingresso no PET, os egressos foram capazes de desenvolver várias habilidades para sua formação pessoal e profissional, concomitantemente aos aspectos cognitivos, sociais e afetivos.

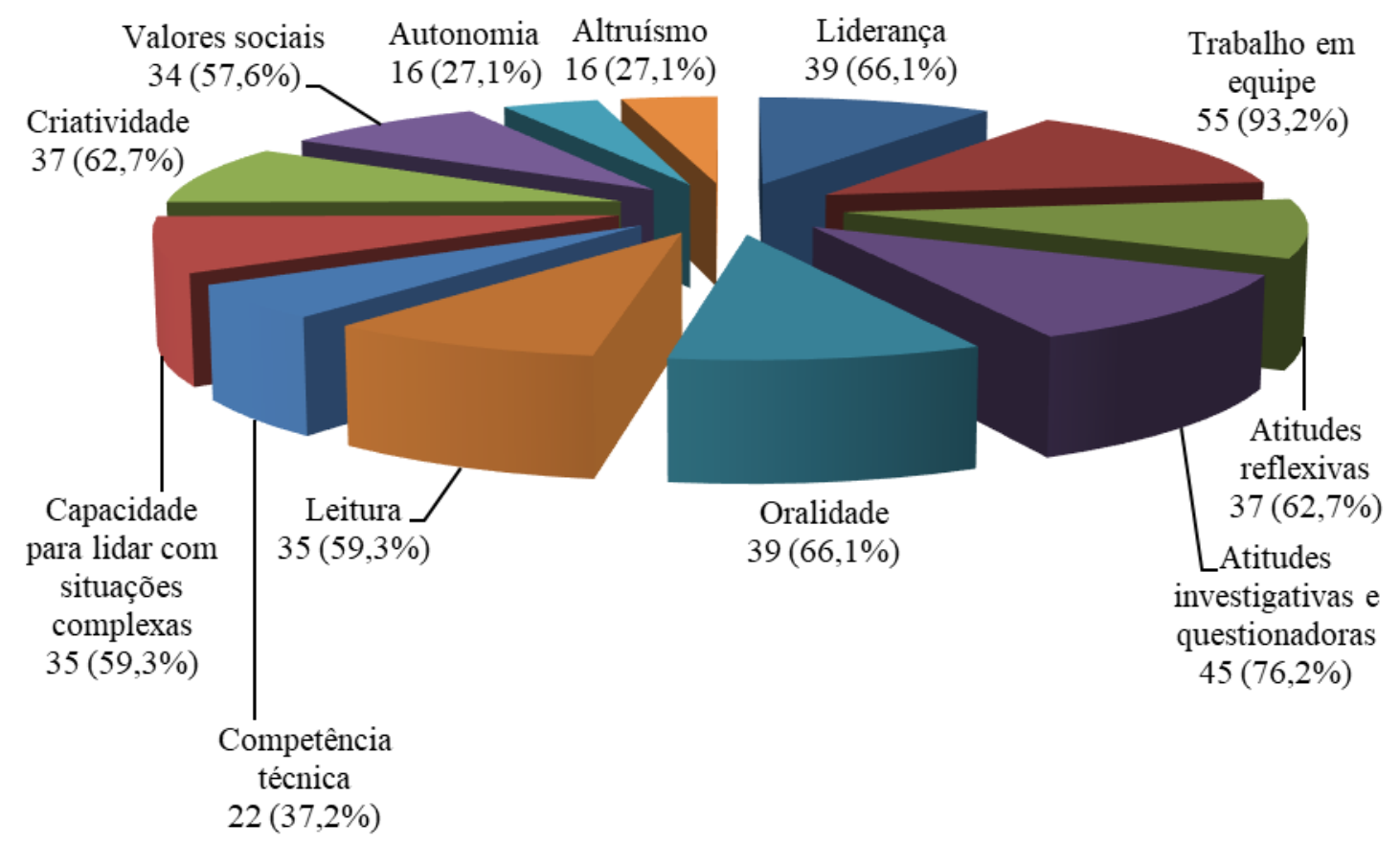

Gráfico 1. Habilidades desenvolvidas a partir da participação no grupo $\operatorname{PET}^{\S}$ (n=59) (múltipla escolha).

No que diz respeito ao conhecimento/ domínio de outros idiomas, a maioria dos egressos respondeu positivamente $(93,2 \%)$.
Para esta parcela, questionou-se quais idiomas eram dominantes, sendo a língua inglesa (54\%) seguida do espanhol (32\%) as principais, 
porém, línguas como francês, árabe, alemão e italiano, mesmo em minoria, também foram relatadas.

Quanto à avaliação dos egressos sobre os objetivos que o PET propõe cumprir no sentido de disseminar novas idéias e práticas, a maioria $(89,8 \%)$ acredita que este objetivo é atingido. Ainda, nota-se que o programa contribuiu com muita intensidade $(62,7 \%)$ para a elevação da qualidade da formação dos bolsistas e também possui a capacidade de estimular a formação de profissionais e docentes para os cursos de Odontologia $(71,2 \%)$ (tabela 3).
Quando solicitado aos egressos a atribuição de um valor numérico para o programa PET, propondo-se essa avaliação em uma escala de intensidade progressiva de 1 até 5 , a maioria $(66,1 \%)$ atribuiu a nota 5 para o programa, considerando-o excelente. Ainda, quando questionados sobre a influência que o PET teve sobre as suas trajetórias profissionais, $19(32,2 \%)$ destacaram uma intensidade de nível 4, e 32 (54,2\%) uma intensidade de nível 5 , corroborando o efeito influenciador que o PET teve sobre suas carreiras profissionais (tabela 3).

Tabela 3. Percepção contributiva e de avaliação do PET

\begin{tabular}{|c|c|c|}
\hline Variável & Categoria & Distribuição n (\%) \\
\hline \multirow{2}{*}{$\begin{array}{l}\text { O PET consegue atingir seu objetivo no sentido de } \\
\text { disseminar novas ideias e práticas aos demais } \\
\text { alunos do curso, por meio da atuação dos bolsistas } \\
\text { como agente multiplicadores? }\end{array}$} & Sim & $53(89,8)$ \\
\hline & Não & $6(10,2)$ \\
\hline \multirow{5}{*}{$\begin{array}{l}\text { O PET consegue atingir seu objetivo no sentido de } \\
\text { contribuir para a elevação da qualidade de } \\
\text { formação acadêmica dos alunos integrantes do grupo } \\
\text { PET em que intensidade? }\end{array}$} & Nenhuma & - \\
\hline & Pouca & - \\
\hline & Moderada & $3(5,1)$ \\
\hline & Muita & $37(62,7)$ \\
\hline & Totalmente & $19(32,2)$ \\
\hline \multirow{5}{*}{$\begin{array}{l}\text { O PET consegue atingir seu objetivo no sentido de } \\
\text { estimular a formação de profissionais e docentes de } \\
\text { elevada qualificação técnica, cientifica, tecnológica e } \\
\text { acadêmica? }\end{array}$} & Nenhuma & - \\
\hline & Pouca & - \\
\hline & Moderada & $3(5,1)$ \\
\hline & Muita & $42(71,2)$ \\
\hline & Totalmente & $14(23,7)$ \\
\hline \multirow[t]{5}{*}{ Como você avalia o programa PET? } & Péssimo & - \\
\hline & 2 Regular & - \\
\hline & Bom & $1(1,7)$ \\
\hline & Muito bom & $19(32,2)$ \\
\hline & Excelente & $39(66,1)$ \\
\hline \multirow{5}{*}{$\begin{array}{l}\text { Você considera que o PET tenha influenciado a sua } \\
\text { trajetória profissional em que intensidade? }\end{array}$} & 1 Péssimo & $1(1,7)$ \\
\hline & Regular & $2(3,4)$ \\
\hline & Bom & $5(8,5)$ \\
\hline & Muito bom & $19(32,2)$ \\
\hline & Excelente & $32(54,2)$ \\
\hline
\end{tabular}


Por fim e não menos importante, a relatou estar muito satisfeito com a profissão satisfação profissional dos egressos, em relação à $\quad(47,5 \%)$, seguidos por uma satisfação moderada carreira, apontou que apenas $1,7 \%$ estão (30,5\%) e totalmente satisfeitos (20,3\%), insatisfeitos e, em contra partida, a maioria conforme elencado na tabela 4.

Tabela 4. Satisfação profissional dos egressos em relação à carreira, de acordo com o gênero

\begin{tabular}{lcccc}
\hline Grau de Satisfação & \multicolumn{2}{c}{ Gênero } & \multicolumn{2}{c}{ Total } \\
& Masculino & Feminino & $\mathbf{n}$ & \% \\
\hline Pouco satisfeito & - & 1 & 1 & 1,7 \\
Moderadamente satisfeito & 6 & 12 & 18 & 30,5 \\
Muito satisfeito & 10 & 17 & 28 & 47,5 \\
Totalmente Satisfeito & 7 & 6 & 12 & 20,3 \\
\hline \multicolumn{1}{c}{ Total } & 23 & 36 & 59 & 100 \\
\hline
\end{tabular}

É lícito conjecturar que os egressos são uma fonte privilegiada de informações que permitem entender o alcance, efeitos e consequências de uma ação educativa. Este estudo talvez seja o mais poderoso e informativo meio para entender a eficácia de um programa e como as práticas e os valores dos sujeitos foram realmente influenciados ${ }^{8}$.

Consideramos que a abordagem dos egressos deve contemplar também uma avaliação das competências traçadas nos objetivos estabelecido pelo Manual de Orientações Básicas do PET $^{12}$, para que efetivamente se possa promover o encontro entre a formação desejada pelo programa e sua efetiva atuação profissional. Se por um lado é importante a análise dos resultados de programas como o PET, por outro existem os desafios na criação de instrumentos e indicadores para tais medidas de avaliação.

No que tange aos egressos deste programa PET com perfil ligado à área da saúde, não vimos diferenças expressivas entre outros estudos que assinalaram igualmente o aprimoramento e a educação continuada dos seus egressos ${ }^{10,12,13}$. A pós-graduação é uma realidade da quase totalidade dos egressos respondentes, conforme exposto na tabela 2. Desafortunadamente, não se observa uma política institucional para a gestão de egressos e, além de não haver muitos estudos publicados, seu acompanhamento é incipiente na maior parte das instituições do Brasil ${ }^{11}$.

O PET, valendo-se da sua premissa de indissociabilidade entre os pilares básicos do saber universitário (ensino, pesquisa e extensão) favorece a quebra da inércia acadêmica tecnicista e da falta de senso crítico, formando profissionais qualificados e compromissados com a sociedade $^{5}$. Atualmente, a filosofia do programa PET busca estimular uma formação mais integral, alicerçada pelas Diretrizes Curriculares Nacionais (DCN), indissociável nos seus pilares fundamentais e de total reversão ao pensamento elitista da época de sua criação, ainda como Programa Especial de Treinamento, quando visava unicamente o fortalecimento da pósgraduação nacional $^{12}$.

Torna-se imperativo que se entenda melhor o alcance das ações desenvolvidas pelo Programa ao longo do tempo, em particular por meio da realização de estudos avaliativos prospectivos que forneçam evidências válidas da eficácia e da utilidade do programa PET no contexto da 
formação de profissionais melhor preparados em suas respectivas áreas profissionais ${ }^{23}$.

Por fim, é importante perceber que o presente estudo corrobora com outros que avaliaram egressos de programas de educação tutorial, no que tange às avaliações objetivas de seus ex-alunos. As vivências metodológicas proporcionadas pelo programa no ensino, na pesquisa e na extensão, aliadas à perspectiva da pedagogia libertadora, determinaram que a participação no programa tenha sido um diferencial positivo e robusto na formação de seus egressos ${ }^{12,13}$.

O conhecimento do perfil do egresso é uma condição de suma importância na compreensão do que se espera de sua trajetória na instituição de ensino superior, atingindo as competências necessárias para o pleno exercício da profissão.

\section{CONCLUSÃO}

Os egressos do PET avaliados no estudo, em sua maioria, estão inseridos no mercado de trabalho em sua área de formação, atuando como profissionais liberais ou docentes, apresentando qualificação profissional advinda de cursos de pós-graduação. O Programa de Educação Tutorial da FO-UFPel vem exercendo um papel importante na trajetória profissional dos egressos, revelando-se como um ponto preponderante e de grande influência na vida de seus ex-bolsistas.

\section{AGRADECIMENTOS}

Os autores agradecem a todos os ex-bolsistas do Programa PET da FO-UFPel que participaram desta pesquisa.

\section{ABSTRACT \\ Evaluation of graduates of the Tutorial Education Program (PET) of the Dentistry Course at the Federal University of Pelotas}

This study evaluated the professional profile of graduates of the School of Dentistry at the
Federal University of Pelotas, participants of the Tutorial Education Program (PET). A descriptive research was conducted, of qualitative and quantitative nature, using a structured and selfadministered electronic questionnaire as collection instrument, sent by email to all graduates who effectively participated in the PET group and agreed to participate in this study. The study assessed the professional activity, training levels and objectives proposed by the program. The total number of graduates was 89 , since the group was created in 1992 until 2019. The answers obtained $(n=59)$ revealed that most graduates who joined the survey completed the course between the years 2004 to 2018 (59.3\%), and only $24(40.6 \%)$ in the period before 2004 . It was found that $25 \%$ work in public services, $44 \%$ in the private sector and $22 \%$ work in both. Concerning the degree, only $4(6.8 \%)$ did not attend postgraduation education, and 53 (89.8\%) work in the Southern region of the country, 36 $(61 \%)$ are females and $23(39 \%)$ are males. At completion of the questionnaire, the participants were asked about the influence of participation in the Program on their professional career, with a scale of progressive intensity from 1 to 5, retrieving 19 responses with score 4 and 39 responses with score 5 . The results evidenced a positive influence from participation in the Program in the professional lives of former participants, both in the job market and in the postgraduation experience.

Descriptors: Dentistry. Education, Higher. Educational Measurement.

\section{REFERÊNCIAS}

1. Teixeira A. Funções da universidade. Boletim Informativo CAPES. Rio de Janeiro, 1964; 135:1-2.

2. Ferreira MM. Produção científica na biblioteconomia: as pesquisas realizadas no Programa de Educação Tutorial (PET) e seus reflexos na formação acadêmica. Rev EDICIC. 2011;1(4):99-108.

3. Carvalho CR, Barros RO, Reis EP, Araújo LB, Sousa HMH. O Programa de Educação Tutorial (PET) no contexto da crise 
econômica brasileira. Rev Ext Foco. 2018;15(1):28-45.

4. Castro CM. A mágica do Dr. Yvon. Belo Horizonte: Benvinda Editora, 2016.

5. Drebes LM, Ortigara C, Artuzo FD, Jandrey WF, Silva VR. A dinâmica do Programa de Educação Tutorial (PET). Enciclop Biosfera. 2012;8(15):2334-51.

6. Souza RM, Gomes Júnior SR. Programa de Educação Tutorial: avanços na formação em física no Rio Grande do Norte. Rev Bras Ens Física. 2015;37(1):1501-5.

7. MEC. Apresentação - PET. Brasília, 02 maio 2020. [Acesso em 2 maio 2020]. Disponível em: http://portal.mec.gov.br/pet.

8. Lordelo JAC, Dazzani MVM. Estudos com estudantes egressos: concepções e possibilidades metodológicas na avaliação de programas. Salvador: EDUFBA, 2012. $173 \mathrm{p}$.

9. Parizotto JOL, Imparato JCP, Novaes TF. Perfil profissional do egresso do programa de pós-graduação em odontopediatria da Faculdade de Odontologia da USP - São Paulo. Rev ABENO. 2015;15(1):48-54.

10. Ferraz MAAL, Nolêto MSC, Martins LLN, Bandeira SRL, Portela SGC, Pinto PHV, et al. Perfil dos egressos do curso de Odontologia da Universidade Estadual do Piauí. Rev ABENO. 2018;18(1):56-62.

11. Senger MH, Campos MCG, Servidoni MFCP, Passeri SMRR, Velho PENF, Toro IFC, et al. Trajetória profissional de egressos do curso de Medicina da Universidade de Campinas (Unicamp), São Paulo, Brasil. Interface. 2018; 22(Supl. 1):1443-55.

12. Silva MLGR. Inserção profissional dos egressos dos Programas de Educação Tutorial (PET) em Administração, Biologia, Economia Doméstica e Nutrição da UFV. [Dissertação]. Universidade Federal de Viçosa, Viçosa, 2015. $171 \mathrm{f}$.
13. Soares FF, Duplat CB, Ferreira LPL, Régis MRS, Reis SRA, Matos MS. Impacto do Programa de Educação Tutorial da Faculdade de Odontologia da Universidade Federal da Bahia na formação profissional dos seus ex-bolsistas. RPG Rev Pós Grad 2010;17(3):143-50.

14. Latreille AC, Machado Sobrinho S, Warmling AMF, Ribeiro DM, Amante CJ. Perfil socioeconômico dos graduandos em Odontologia da Universidade Federal de Santa Catarina. Rev ABENO. 2015;15 (1):86-96.

15. Granja GL, Santos TL, Mariz RC, Araki MT, Vieira e Souza S, Nunes JMFF, et al. Perfil dos estudantes de graduação em Odontologia: motivações e expectativas da profissão. Rev ABENO. 2016;16(4):107-13.

16. Saliba NA, Moimaz SAS, Prado RL, Garbin CAS. Percepção do cirurgião-dentista sobre formação profissional e dificuldades de inserção no mercado de trabalho. Rev Odontol UNESP. 2012; 41(5):297-304.

17. Santos AM, Rodrigues AAAO, Suzuki CLS, Magalhães DC, Brandão PTJ, Batista RL, et al. Mercado de trabalho e a formação dos estudantes de Odontologia: paradigma da mudança. Rev Saúde Com. 2006;2(2):169182.

18. Leite DFBM, Trigueiro M, Martins IMCLB, Lima Neto TJ, Santos MQ. Perfil socioeconômico de 253 graduandos de Odontologia de uma instituição privada em João Pessoa-PB em 2011. J Health Sci Inst. 2012;30(2):117-9.

19. Oliveira DL, Souza ES, Batista FJN, Alves JV, Yarid SD. Perfil do aluno de Odontologia da Universidade Estadual do Sudoeste da Bahia - UESB. Rev Saúde Com. 2013; 9(3):169-78.

20. Marques MD, Souza CA, Pazos CTC, Amaral DS, Vieira EG, Campos WCS, et al. 
Expectativas dos estudantes de Odontologia quanto ao futuro profissional. Rev ABENO. 2015;15(3):60-8.

21. Pinheiro VC, Menezes LMB, Aguiar ASW, Moura WVB, Almeida MEL, Pinheiro FMC. Inserção dos egressos do curso de Odontologia no mercado de trabalho. RGO. 2011;59(2):277-83.
22. Mialhe FL, Furuse R, Gonçalo CS. Perfil profissional de uma amostra de egressos da Faculdade de Odontologia de Piracicaba. UFES Rev Odontol. 2008;10(2):31-6.

23. Dantas F. O PET e a formação de lideranças acadêmicas e profissionais. INFOCAPES 23. 1995;3(1-2):18-20.

\section{Correspondência para:}

Josué Martos

e-mail: josue.sul@ terra.com.br

Faculdade de Odontologia

Universidade Federal de Pelotas

Rua Gonçalves Chaves 457.

96015-560 Pelotas/RS 